\title{
Factors associated with early sexual initiation among preparatory and high school youths in Woldia town, northeast Ethiopia: a cross-sectional study
}

Eskeziaw Abebe Kassahun ${ }^{*}$, Abebaw Addis Gelagay ${ }^{2}$, Achenef Asmamaw Muche ${ }^{3}$, Amanuel Addisu Dessie ${ }^{4}$ and Belayneh Ayanaw Kassie ${ }^{5}$

\begin{abstract}
Background: Early initiation of sexual activity affects the sexual and reproductive health of the young population. The youth are at a high risk of risky sexual behaviours, including multiple partners and inconsistent condom use. There has been limited research on the level and determinants of early sexual initiation in Woldia town. Thus, this study aimed to assess the prevalence of early sexual initiation and associated factors among preparatory and high school students in Woldia town, northeast Ethiopia.

Methods: An institution based cross-sectional study was conducted on 723 students selected by the simple random sampling technique on March 7, 2016. A pre-tested and structured self-administered questionnaire was used for data collection. Descriptive statistics, bivariate and multivariable logistic regression were computed. Adjusted odds ratio (AOR) with a 95\% confidence interval (Cl) was calculated to examine the strength of association. In the multivariable analysis, a $p$-value $<0.05$ was considered as statistically significant.
\end{abstract}

Result: The prevalence of early sexual initiation among preparatory and high school students in Woldia town was 18.4\% (95\% Cl:15.50,21.30\%). Not attending religious programs ( $\mathrm{AOR}=3.2,95 \% \mathrm{Cl}: 1.84,5.44)$, peer pressure (AOR $=1$. 9, 95\% Cl:1.14,3.25), cigarette smoking ( $\mathrm{AOR}=2.3,95 \% \mathrm{Cl}: 1.06,4.85)$, poor parental monitoring (AOR $=2.8,95 \% \mathrm{Cl}: 1$. 77,4.53), and exposure to pornographic materials (AOR $=2.7,95 \% \mathrm{Cl}: 1.68,4.40)$ were significantly associated with early sexual initiation.

Conclusion: A large number of students initiated sexual activity at an early age. The practiced is associated with sexual and reproductive health problems. Therefore, raising awareness of students about the risk factors for and implication of early sexual initiation through teachers, religious leaders, and parents is highly recommended.

Keywords: Early sexual initiation, Youth, Students, Woldia, Ethiopia

\section{Background}

The World Health Organization (WHO) defines youth as a group of people between the ages of 15 to 24 years which is characterized by a rapid progression from the appearance of secondary sexual characteristics to sexual and reproductive maturation. This period is also the time when youth face many challenges. The decisions

\footnotetext{
* Correspondence: eskeziaw02@gmail.com

${ }^{1}$ Department of Midwifery, Faculty of Health Sciences, Woldia University, Woldia, Ethiopia

Full list of author information is available at the end of the article
}

they make during this vulnerable period can impact the quality and length of their life $[1,2]$.

Early initiation of sex exposes young people to many sexual and reproductive health problems. Youth who begin early sexual activity are more likely to practice risky sexual behaviours, such as multiple sexual partners and incorrect or inconsistent condom use. As a result, they increase the risk of sexually transmitted infection (STIs), including HIV/ AIDS, unwanted pregnancy, unsafe abortion, early childbirth, and psychosocial problems. These problems are the greatest threats to health and wellbeing of the youth [3, 4]. 
According to the 2016 Ethiopian Demographic and Health Survey (EDHS) report, 24 and $62 \%$ of women initiated sex before the ages of 15 and 18 years, respectively [5].

Globally, adolescent and youth represent a growing share of people living with HIV/AIDS. Each year, 670,000 youth are infected with HIV. Of these, 250,000 are adolescents [6], and 16 million of them give birth [7].

In Africa, a high proportion of unsafe abortions are among adolescents and young women. About $60 \%$ of the unsafe abortions occur among women under 25 years [8].

In Ethiopia, unwanted pregnancy among adolescent and the youth is the major sexual and reproductive health challenge. Fifty-four percent of women under the age of 15 years and $37 \%$ of youth aged $20-24$ years have an unwanted pregnancies [9].

Numerous socio-demographic, economic, behavioral, and parental characteristics, including age [10-12], sex [13-18], residence [12, 17], parental monitoring $[11,19,20]$, behavioral factors $[13,15,16,18,19]$ and peer pressure $[11,12]$ were significantly aassociated with early sexual initiation.

There has been only limited information on the magnitude of early sexual initiation and associated factors among the youth in northeast Ethiopia, particularly in the study area. Understanding and identifying factors associated with early sexual initiation are essential for developing effective policies and strategies to reduce the adverse consequences of early sexual initiation. Therefore, this study aimed to assess the prevalence and risk factors of early sexual initiation among preparatory and high school students in Woldia town, northeast Ethiopia.

\section{Methods}

\section{Study setting and period}

An institution based cross-sectional study was conducted on March 7, 2016 in Woldia, northeast Ethiopia. Woldia is found $520 \mathrm{~km}$ from Addis Ababa, the capital of Ethiopia. According to the 2016 Woldia town administrative report, the estimated population was 75,446 , of which $50.6 \%$ were males [21]. In the town, there was one preparatory and three high schools with a total of with a total of 4671 students. There were 87 sections, of these 59 sections were in high schools.

\section{Sample size and sampling procedures}

All regular preparatory and high school students in the town during the study were included. The required sample size was calculated using the single population proportion formula by considering a 95\% confidence interval (CI), 3\% margin of error(d), and the proportion(p) of early sexual debut $19 \%$ from the previous study in Shire-Endasellassie town, Tigray region [22]. Considering a $10 \%$ non-response rate, the final sample was 723 students. The simple random sampling technique with proportional allocation to each grade level was applied to reach participants. Thus, 269, 177, 143 and 129 students were selected from grade $9,10,11$, and 12 , respectively.

\section{Data collection tool and techniques}

The data were collected using a structured self-administered questionnaire (Additional file 1). The questionnaire was first prepared in English and translated to Amharic (the local language) and back-translated into English by language experts to ensure an accurate translation. Ten data collectors were selected from Woldia University 4th year Midwifery students. Interviewers received 2 days intensive training prior to data collection. The questionnaire was pretested on 37 students in Kobo preparatory and high school out of the study area. The purpose and objectives of the study were clearly explained to participants before data collection. No personal identifiers were used on data collection forms, and teachers were requested to leave the classroom. To maintain privacy, seats were arranged far apart and copies were collected on the ballot.

\section{Measurements}

\section{Age at sexual initiation}

The age at which students had penetrative sexual intercourse from the first time.

\section{Early sexual initiation}

Having sexual practice before the age of 18 years.

\section{Sexually active}

Students who claimed to have engaged in sexual activity at least once prior to the study.

\section{Peer pressure}

Pressure from friends to have sexual intercourse.

\section{Pornographic materials}

Refers to newspapers, magazines, books, photographs, movies, the internet intended to sexually arouse the viewer.

\section{Religious participation}

Student participation in religious programs.

\section{Assessment of wealth index and parental monitoring}

Household wealth index adopted and developed from EDHS 2011 [23] was assessed using Principal Component Analysis (PCA) by considering the numbers and kinds of goods ranging from television to car, agricultural land ownership, quantity of cereal products, 
livestock and housing condition, such as flooring materials, household cooking material and place. Firstly, variables were coded between 0 and 1 ; then, the variables were entered and analyzed using PCA. Variables which had communality values greater than 0.5 were considered to produce factor scores. Next, the produced factor scores were computed to produce common factor scores. Finally, common factor scores were summed and categorized into quintile as lowest, second, middle, fourth, and highest. Similarly, paternal monitoring was assessed using a four-item Likert scale which was adapted and developed from previous studies [24, 25]. The items used to assess parental monitoring were 'How often do your parents try to know who are your friends', 'Do your parents know where you are outside of home or school' and 'Do your parents know with whom you are outside home or school'. The responses ranged from 'never' (coded as 1) to 'always' (coded as 4). Finally, via PCA, it was classified as 'poor' and 'good' parental monitoring.

\section{Assessment of school connectedness and knowledge of HIV/AIDS}

Student school connectedness was assessed using a five-item Likert scale adopted and developed from a previous study [26], such as 'Do you feel close to people who are at school', 'Do you feel happy to be at this school,' 'Do you feel as if you are a part of this school', 'Do school teachers treat students fairly at this school', and 'Do you feel safe being at this school'. The responses ranged from 'strongly disagree' (coded 1) to 'strongly agree' (coded as 5). Using PCA, the scale was classified into quantiles as poor and good school connectedness. In addition, knowledge of students on HIV/AIDS was assessed based on the transmission and prevention methods of HIV/AIDS which was adopted from EDHS 2011 [23], and the questions included condom use, number of sexual partners, awareness on healthy-looking person may have HIV/AIDS, and rejection of the two most common local misconceptions about HIV/AIDS that (HIV/AIDS can be transmitted by mosquito bite and supernatural means). Using PCA, the scale was ranked into 'poor' and 'good' knowledge.

\section{Data processing and analysis}

After the data collection, the data were checked for completeness, coded manually, and entered into EpiData version 3.1 and then exported to SPSS version 20 for analysis. Descriptive analysis was carried out and presented using texts, tables, and graphs. Bivariate and multivariable logistic regression analysis were done to identify factors associated with early sexual initiation. Variables in the bivariate logistic regression with $p$-value less than 0.2 were fitted into the multivariable logistic regression to control the possible effects of confounders. The enter method was employed. Odds Ratios with their corresponding 95\% confidence intervals (CI) was calculated to see the presence and the strength of associations. Model fitness was checked by the Hosmer-Lemeshow goodness of-fit test. In the multivariable analysis, variables with $p$-value $<0.05$ were considered as statistically significant.

\section{Results \\ Socio-demographic and economic characteristics of participants}

A total of 718 students participated in the study with a response rate of $99.3 \%$. The median age of the participants was 17 (IQR \pm 1.6$)$ years. Approximately, half $(50.7 \%)$ of the students were female. The majority $(91.8 \%)$ were in the age range of 15-19 years. In addition, $59.2 \%$ of the students did not take life skills training, and 15.6 and $7.7 \%$ had deceased fathers and mother, respectively, (Table 1).

\section{Parental communication and monitoring, school connectedness, and peer pressure}

About $46 \%$ of students reported that their parents strongly monitored them, and $49.6 \%$ said they had good school connectedness. Moreover, $55.3 \%$ of the participants discussed at least one sexual and reproductive health issue with their parents. The most common sexual and reproductive health issue which students discussed with their parents was on HIV/AIDS (Table 2).

\section{Behavioral characteristics}

Among the study participants, 39.4, 7.8, 17.3 and 45\% reported that they drank alcohol, smoked cigarettes, chewed khat, and were exposed to pornographic materials, respectively, (Fig. 1).

\section{Prevalence of early sexual initiation}

The overall prevalence of early sexual initiation in the study area was $18.4 \%$ (95\% CI:15.50\%, 21. 30\%). Out of the participants, $38.3 \%$ were sexually active, of whom $55.5 \%$ initiated the first sex with their regular boy/girlfriends and $56.7 \%$ had two or more sexual partners (Table 3).

\section{Factors associated with early sexual initiation}

In the bivariate logistic regression analysis, sex, marital status, educational status, attending religious programs, parent-youth discussion, drinking alcohol, smoking cigarettes, chewing khat, smoking shisha, life skills training, parental monitoring, school connectedness, peer pressure, and exposure to pornographic materials were associated with early sexual initiation at $p$-value $<0.2$. In the multivariable logistic regression analysis, sex, attending 
Table 1 Socio-demographic characteristics of preparatory and high school students, Woldia, northeast Ethiopia 2016 $(n=718)$

\begin{tabular}{lll}
\hline Variables & Frequency & Percentage \\
\hline Sex & & \\
Female & 364 & 50.7 \\
Male & 354 & 49.3 \\
Age & & \\
$15-19$ & 659 & 91.8 \\
$20-24$ & 59 & 8.2 \\
Marital status & & \\
Single & 714 & 99.4 \\
Married & 4 & 0.6
\end{tabular}

Educational status

Grade 9

Grade 10

Grade 11

Grade 12

Religion

Orthodox Christian 517

Muslim 182

Others $^{\mathrm{a}}$

Religious participation

Yes

No

90

Frequency of religious participation $(n=628)$

$\begin{array}{ll}\text { Every day } & 23 \\ \text { Once a week } & 289 \\ \text { Once a month } & 52 \\ \text { Once a year } & 40 \\ \text { Others }^{b} & 16 \\ \text { iving with } & \end{array}$

Both parents 388

Mother only 109

Father only 24

Friends 21

Relative 133

Living alone 42

Grandparents 21

Current Fathers' educational status $(n=606)$

Unable to write and read $\quad 60$

Able to write and read 239

Elementary school (1-8th) $\quad 127$

High school (9-10th) 22

Preparatory school (11-12th) $\quad 36$

Collage and above
Table 1 Socio-demographic characteristics of preparatory and high school students, Woldia, northeast Ethiopia 2016 $(n=718)$ (Continued)

\begin{tabular}{|c|c|c|}
\hline Variables & Frequency & Percentage \\
\hline \multicolumn{3}{|c|}{ Current Mother's educational status ( $n=663$ ) } \\
\hline Unable to write and read & 129 & 19.5 \\
\hline Able to write and read & 195 & 29.4 \\
\hline Elementary school (1-8th) & 124 & 18.7 \\
\hline High school (9-10th) & 71 & 10.7 \\
\hline Preparatory school (11-12th) & 52 & 7.8 \\
\hline Collage and above & 92 & 13.9 \\
\hline \multicolumn{3}{|c|}{ Current Father's employment status $(n=606)$} \\
\hline Civil servant & 181 & 25.2 \\
\hline Private employer & 99 & 13.8 \\
\hline Merchant & 115 & 16.0 \\
\hline Daily laborer /house maid & 17 & 2.4 \\
\hline Farmer & 172 & 24.0 \\
\hline Others $^{c}$ & 22 & 3.1 \\
\hline \multicolumn{3}{|c|}{ Current Mother's employment status ( $n=663$ ) } \\
\hline House wife & 310 & 46.8 \\
\hline Civil servant employer & 121 & 18.3 \\
\hline Private employer & 46 & 7.0 \\
\hline Merchant & 119 & 18.0 \\
\hline Daily laborer /house maid & 16 & 2.4 \\
\hline Farmer & 51 & 7.7 \\
\hline \multicolumn{3}{|l|}{ Household wealth status } \\
\hline Lowest & 143 & 19.9 \\
\hline Second & 258 & 35.9 \\
\hline Middle & 35 & 4.9 \\
\hline Fourth & 142 & 18.9 \\
\hline Highest & 140 & 18.5 \\
\hline
\end{tabular}

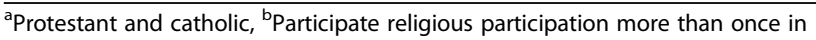
a week, month, and year ' Driver, Soldier, Pensioner

religious programs, peer pressure, smoking cigarettes, parental monitoring, and pornographic materials remained statistically significant and were independently associated with early sexual initiation. The odds of having early sexual initiation were three times $(\mathrm{AOR}=3.2$; 95\% CI: $1.84,5.44)$ as high among students who didn't attend religious programs compared to their counterparts. Similarly, the odds of having early sexual initiation were nearly three times (AOR $=2.8 ; 95 \% \mathrm{CI}: 1.77,4.53)$ as high among students who had poor parental monitoring than those who had good parental monitoring. Compared to students who had not been exposed to peer pressure, students who had peer pressure were at increased odds of having early sexual initiation by $90 \%$ $(\mathrm{AOR}=1.9 ; 95 \% \mathrm{CI}: 1.14,3.25)$. Moreover, early sexual initiation was about three times $(\mathrm{AOR}=2.7 ; 95 \% \mathrm{CI}$ : 
Table 2 Parental communication and monitoring, school connectedness and peer pressure of school students in Woldia, northeast Ethiopia, $2016(n=718)$

\begin{tabular}{|c|c|c|}
\hline Variables & Frequency & Percentage \\
\hline \multicolumn{3}{|l|}{ Parental monitoring } \\
\hline Poor & 329 & 45.8 \\
\hline Good & 389 & 54.2 \\
\hline \multicolumn{3}{|l|}{ School connectedness } \\
\hline Poor & 362 & 50.4 \\
\hline Good & 356 & 49.6 \\
\hline \multicolumn{3}{|l|}{ Parent-youth communication on SRH issue } \\
\hline Yes & 397 & 55.3 \\
\hline No & 321 & 44.7 \\
\hline \multicolumn{3}{|c|}{ Parent-youth communication on $(n=397)^{\oplus}$} \\
\hline Puberty and menstruation & 175 & 44.1 \\
\hline Prevention of pregnancy & 91 & 22.9 \\
\hline Relationship with opposite sex & 122 & 30.7 \\
\hline Unwanted pregnancy and abortion & 81 & 20.4 \\
\hline STIs including HIVI/AIDS & 205 & 51.6 \\
\hline Discussion on other issues ${ }^{a}$ & 6 & 1.5 \\
\hline \multicolumn{3}{|l|}{ Peer pressure to have sex } \\
\hline Yes & 110 & 15.3 \\
\hline No & 608 & 84.7 \\
\hline
\end{tabular}

${ }^{\circledR}$ multiple responses ${ }^{\mathrm{a} O n}$ pregnancy, Rape, Sexual abuse

$1.68,4.40)$ as high among students exposed to pornographic materials than their counterparts (Table 4).

\section{Discussion}

This study was conducted to assess the prevalence and factors associated with early sexual initiation among preparatory and high school students in Woldia town, northeast Ethiopia. The overall prevalence of early sexual initiation among preparatory and high school students in Woldia was $18.4 \%$ (95\% CI; 15.50, 21.30\%). This finding is quite similar to those of other local studies carried out in Shire-Endasellassie town, Tigray region (19\%) [18] and

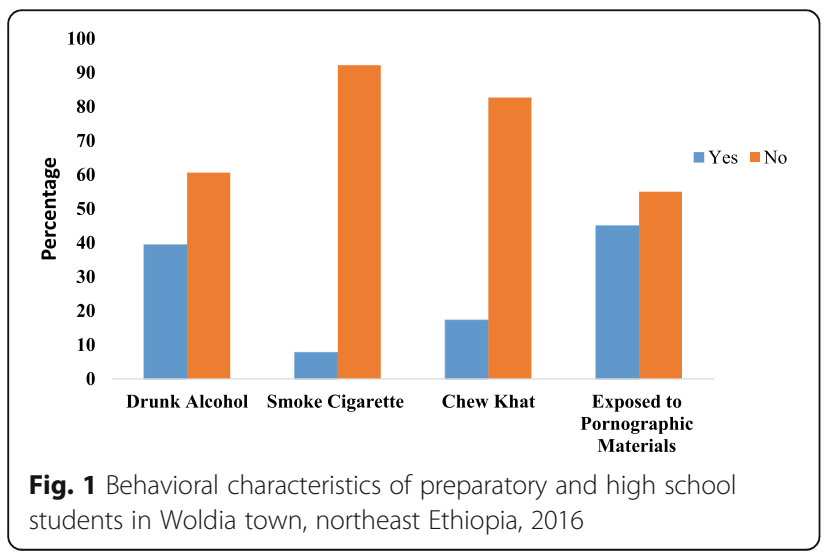

Table 3 Sexual history of preparatory and high school students in Woldia, northeast Ethiopia, 2016 $(n=718)$

\begin{tabular}{lll}
\hline Variable & Frequency & Percentage \\
\hline Ever had sex & 275 & 38.3 \\
Yes & 443 & 61.7 \\
No & & \\
First sexual partner ( $n=275)$ & 153 & 55.5 \\
$\quad$ Regular boy/girl friend & 64 & 23.3 \\
Casual partner & 3 & 1.1 \\
Husband or wife & 10 & 3.6 \\
Family member & 27 & 9.8 \\
Teacher & 18 & 6.5 \\
Commercial worker & & \\
Number of life time sexual \\
partner ( $n=275)$
\end{tabular}

Faggeta-Lekoma district, Awi Zone (20.4\%) [11], Ethiopia. This finding is lower than reports in Addis Ababa (25.4\%) [27] and the EDHS 2016 report (62\%) [5]. The difference may be accounted for by time trends. There is an increasing impact of globalization or new technologies that influence the healthy sexual life of students. Furthermore, the possible difference from the EDHS result might be variations of study areas in that the EDHS study was conducted in both urban and rural areas of all regions of Ethiopia which had different socio-cultural characteristics and access to youth reproductive health services. Additionally, in the rural areas of Ethiopia, family arranged marriages at young age are common.

Girls were more likely to initiate sexual intercourse before the age of 18 years than boys. This finding is in line with those of other studies in Ethiopia, such as EDHS 2016 [5], Dessie [28] and Debre-Markose [13]. This might be due to the effect of culture that forces females to marry at young age. Besides, boys have greater access to education than girls.

Religious institutions have been focusing on advising and counseling individuals to delay sexual initiation and discourage sex before marriage, substance use, and multiple sexual partners. Generally, religious institutions play an important role in youth to develop healthy lifestyle. In this study, students who participated in religious education programs were less likely to initiate sex at an early age. The finding is in line with those of other studies done in USA [29], and Addis Ababa, Ethiopia [30]. 
Table 4 Bivariate and multivariable analysis for early sexual initiation among preparatory and high school students in Woldia town, northeast Ethiopia, 2016 $(n=718)$

\begin{tabular}{|c|c|c|c|c|c|}
\hline \multirow[t]{2}{*}{ Variables } & \multicolumn{2}{|c|}{ Early sexual initiation } & \multirow[t]{2}{*}{ COR $(95 \% \mathrm{Cl})$} & \multirow[t]{2}{*}{$P$-value } & \multirow[t]{2}{*}{ AOR $(95 \% C l)$} \\
\hline & Yes & No & & & \\
\hline \multicolumn{6}{|l|}{ Sex } \\
\hline Female & 52 & 302 & $1.6(1.11,2.40)$ & 0.012 & $3.0(1.88,4.76)^{* *}$ \\
\hline Male & 80 & 284 & 1.0 & & \\
\hline \multicolumn{6}{|l|}{ Religious participation } \\
\hline No & 36 & 54 & $3.7(2.3,5.9)$ & 0.000 & $3.2(1.84,5.44) * *$ \\
\hline Yes & 96 & 532 & 1.0 & & 1.0 \\
\hline \multicolumn{6}{|l|}{ Peer pressure } \\
\hline Yes & 40 & 70 & $3.2(2.05,5.01)$ & 0.000 & $1.9(1.14,3.25)^{*}$ \\
\hline No & 92 & 516 & 1.0 & & 1.0 \\
\hline \multicolumn{6}{|l|}{ Drinking alcohol } \\
\hline Yes & 80 & 203 & $2.9(1.97,4.28)$ & 0.000 & $1.5(0.90,2.35)$ \\
\hline No & 52 & 383 & 1.0 & & 1.0 \\
\hline \multicolumn{6}{|l|}{ Cigarette smoking } \\
\hline Yes & 26 & 30 & $4.6(2.58,8.00)$ & 0.000 & $2.3(1.06,4.85) *$ \\
\hline No & 106 & 5156 & 1.0 & & 1.0 \\
\hline \multicolumn{6}{|l|}{ Khat Chewing } \\
\hline Yes & 47 & 77 & $3.7(2.38,5.62)$ & 0.000 & $1.6(0.90,2.78)$ \\
\hline No & 85 & 509 & 1.0 & & 1.0 \\
\hline \multicolumn{6}{|l|}{ Smoking shisha } \\
\hline Yes & 12 & 27 & $2.1(1.02,4.20)$ & 0.044 & $0.6(0.26,1.62)$ \\
\hline No & 120 & 559 & 1.0 & & 1.0 \\
\hline \multicolumn{6}{|l|}{ Life skills training } \\
\hline No & 92 & 333 & $1.8(1.17,2.62)$ & 0.007 & $1.4(0.89,2.25)$ \\
\hline Yes & 40 & 253 & 1.0 & & 1.0 \\
\hline \multicolumn{6}{|l|}{ Parental monitoring } \\
\hline Poor parental monitoring & 94 & 235 & $3.7(2.45,5.58)$ & 0.00 & $2.8(1.77,4.53)^{* *}$ \\
\hline Good parental monitoring & 38 & 351 & 1.0 & & 1.0 \\
\hline \multicolumn{6}{|l|}{ School connectedness } \\
\hline Poor school connected & 88 & 274 & $2.3(1.53,3.39)$ & 0.000 & $1.3(0.83,2.14)$ \\
\hline Good school connected & 44 & 312 & 1.0 & & 1.0 \\
\hline \multicolumn{6}{|c|}{ Exposed to pornographic materials } \\
\hline Yes & 169 & 177 & $3.7(2.45,5.56)$ & 0.000 & $2.7(1.68,4.40) * *$ \\
\hline No & 68 & 358 & 1.0 & & 1.0 \\
\hline
\end{tabular}

Note: ${ }^{*}(P$-value $<0.05)$ and ${ }^{* *}(P$-value $<0.01)$

In addition, students who smoked cigarettes were more likely to start sex at an early age. The same finding was noticed by other studies done in Debre-Markose [13], China [31], and Addis Ababa [30].This might be due to the effect of substance which alters healthy thinking ability of the youth and results in unplanned and unsafe sex.

Students who had good parental monitoring were less likely to start sexual activity early than those who had poor parental monitoring. This is consistent with studies done in Awi Zone [11], Kenya [32], and Nekemte [25]. Effective parental monitoring of children's behavior, attitude, and values has a significant role in reducing poor decision making on sexual and reproductive life [28].

Furthermore, in this study, students who were exposed to pornographic materials were more likely to initiate sexual activity before the age of 18 years. This finding agrees with those of other studies conducted in 
Shire-Endasellassie town [18], Alamata [12], and Bahir Dar [17], Ethiopia. This could be due to the fact that pornographic materials can stimulate psychological and mental sexual desire and empress to experiment what has been observed. The impulsive nature of pornographic materials lead to erotic sexual stimulation or early sexual practice $[33,34]$.

\section{Limitations of the study}

Since sexual practice has private, intimate, and sensitive nature in the society, there might be an underreporting of some behaviours. However, the principal investigator used self-administered questionnaire so as to maintain privacy and informed participants about the purpose of the study and the importance of telling the truth.

\section{Conclusion}

A significant proportion of students had sexual practice before the age of 18 years. Not attending religious programs, peer pressure, smoking cigarettes, poor parental monitoring, and watching/reading pornographic materials were significantly associated with early sexual initiation. The authors recommended increasing awareness and educating students to delay sexual practice, avoid substance use, and viewing or reading pornographic materials. The recommendation to families is to monitor their children and support them to have good school connectedness.

\section{Additional file}

Additional file 1: English version research questionnaire used to assess the factors associated with early sexual initiation among preparatory and high school youths in Woldia town, northeast Ethiopia: A cross-sectional study. (DOCX $30 \mathrm{~kb}$ )

\section{Abbreviations}

AOR: Adjusted Odds Ratio; Cl: Confidence Interval; COR: Crude Odds Ratio; EDHS: Ethiopian Demographic and Health Survey; IQR: Inter Quartile Range; PCA: Principal Component Analysis; SPSS: Statistical Package for Social Sciences; SRH: Sexual and Reproductive Health; UNICEF: United Nations Children's Fund; USA: United States of America

\section{Acknowledgements}

The authors would like to acknowledge study participants for their participation in the study. They are also special gratitude to University of Gondar and Woldia University for material support. Finally, authors would like to thank Professor Gillian H. Ice (Ph.D., M.P.H) and Mr. Birhanu Tadege (BSC, MSc) for his valuable contribution to revised the manuscript.

\section{Funding}

Not applicable.

\section{Availability of data and materials}

The datasets used and/or analyzed during the current study are available from the corresponding author (Eskeziaw Abebe; eskeziaw02@gmail.com) on reasonable request.

\section{Authors' contributions}

EAK and AAG developed the idea of the study, EAK acquired the research proposal, facilitated data collection, carried out statistical analysis and draft the manuscript. $A A G, A A M, A A D$ and BAK participated in the design of the study and proposal development, statistical analysis and critically reviewed the manuscript. All authors prepared, read and approved the manuscript.

\section{Authors' information \\ EAK: MPH in Reproductive Health, works at Woldia University, Ethiopia, AAG: Assistant Professor of Reproductive Health, works at University of Gondar, Ethiopia, AAM: MPH in Field Epidemiology, PhD candidate, works at University of Gondar, Ethiopia, AAD: MPH in General Public Health, works at Woldia university, Ethiopia, and BAK: MPH in Reproductive Health, works at University of Gondar, Ethiopia.}

\section{Ethics approval and consent to participate}

Ethical approval was obtained from the Institutional Review Board of the University of Gondar. A permission letter was obtained from the University of Gondar, Institution of Public Health. During data collection, adequate information was given to the participants about the purpose, procedures, potential risks, and the benefits of the study to encourage the provision of accurate and honest responses. A written consent was obtained from parents or legal guardians for participants who were less than 18 years of age. Moreover, verbal assent was secured from the youth aged below 18 years. Those who were aged 18 years and above, provided written consent on their own. Confidentiality of responses was ensured by the anonymity of the self- administered questionnaire. No school community members accessed the questionnaire.

\section{Consent for publication}

Not applicable.

\section{Competing interests}

The authors declare that they have no competing interests

\section{Publisher's Note}

Springer Nature remains neutral with regard to jurisdictional claims in published maps and institutional affiliations.

\section{Author details}

${ }^{1}$ Department of Midwifery, Faculty of Health Sciences, Woldia University, Woldia, Ethiopia. ${ }^{2}$ Departments of Reproductive Health, Institute of Public Health, College of Medicine and Health Sciences, University of Gondar, Gondar, Ethiopia. ${ }^{3}$ Department of Epidemiology and Biostatistics, Institute of Public Health, College of Medicine and Health Sciences, University of Gondar, Gondar, Ethiopia. ${ }^{4}$ Department of Public Health, Faculty of Health Sciences, Woldia University, Woldia, Ethiopia. ${ }^{5}$ ICAP/NEPI project, College of Medicine and Health Sciences, University of Gondar, Gondar, Ethiopia.

Received: 20 March 2018 Accepted: 19 March 2019

Published online: 04 April 2019

\section{References}

1. World Health Organization (WHO). Programming for adolescent health and development: Report of a WHO/UNFPA/UNICEF study group on programming for adolescent health; Geneva, 1999.

2. Khan S, Mishra V. Youth Reproductive and Sexual Health,DHS Comparative Calverton. Maryland: Macro International; Geneva, 2008.

3. Sheehefer MT, Rew L. Risky sexual behavior among adolescent women. J Spec Pediatr Nurs. 2000;5(1).

4. Mensch BS, Grant MJ, Blanc AK. The changing context of sexual initiation in sub-Saharan Africa. Popul Dev Rev. 2006;32:699-727.

5. Central Statistical Agency (CSA) [Ethiopia] and ICF. Ethiopia Demographic and Health Survey 2016. Addis Ababa, Ethiopia, and Rockville, Maryland, USA: CSA and ICF; 2016

6. United Nations Children's Fund(UNICEF). Adolescents and young people 2016.

7. World Health Organization(WHO). Why Is Giving Special Attention to Adolescents Important for Achieving Millennium Development Goal 5? Fact sheet, WHO/MPS/0814; 2008

8. Mesce D, Sines E. Unsafe abortion: facts and figures; Washington, DC, 2006. 
9. Federal Ministry of Health(FMOH). National reproductive health strategy. 2006-2015.

10. Tavares CM, Schor N, Junior IF, Diniz SG. Factors associated with sexual initiation and condom use among adolescents on Santiago Island, Cape Verde, West Africa. Cad Saúde Pública, Rio de Janeiro. 2009;25(9):1969-80.

11. Bizu D, Aderaw Z, Kassa GM. Assessment of early sexual initiation and associated factors among preparatory school students of FaggetaLekoma District, Awi zone, Northwest Ethiopia. Int J Clin Med. 2015;6:521-9.

12. Kassa GM, Woldemariam EB, Moges NA. Prevalence of Premarital Sexual Practice and Associated Factors among Alamata High School and Preparatory School Adolescents, Northern Ethiopia. Glob J Med Res. 2014;14(3).

13. Kassa GM, Tsegay G, Abebe N, Bogale W, Tadesse T, Amare D, et al. Early sexual initiation and associated factors among Debre Markos University students. NW Ethiopia Sci J Clin Med. 2015;4(5):80-5.

14. Bizuayehu HM, Abyu DM, Demessie HF. Assessment of time of sexual initiation and its associated factors among students in Northwest Ethiopia. Sci J Public Health. 2015;3(1):10-8

15. O'Donnell L, O'Donnell CR, Stueve A. Early sexual initiation and subsequent sexrelated risks among urban minority youth. Columbia Fam Plann Perspect. 2001; 33(6):268-75

16. Fatusi $\mathrm{AO}$, Blum RW. Predictors of early sexual initiation among a nationally representative sample of Nigerian adolescents. BMC Public Health. 2008;8(136).

17. Mulu W, Yimer M, Abera B. Sexual behaviours and associated factors among students at Bahir Dar University: a cross sectional study. Reprod Health. 2014;11(84).

18. Ayalew A, Abreha K, Shumey A, Berhane K. Magnitude and predictors of early sexual debut among high and preparatory school students in northern Ethiopia: a school-based Crosssectional study. Health Educ Res Dev. 2015;3(3):151.

19. Tilahun M, Ayele G. Factors associated with age at first sexual initiation among youths in Gamo Gofa. SW Ethiopia BMC Public Health. 2013;13:13.

20. Marston M, Beguy D, Kabiru C, Cleland J. Predictors of sexual debut among young adolescents in Nairobi's informal settlements. Europe PMC Funders Group. 2014;39(1):22-31.

21. Woldia town health office report. Woldia town estimated total population size. Woldia, Ethiopia; 2011

22. Abreha K, Shumey A, Berhane K. Magnitude and Predictors of Early Sexual Debut among High and Preparatory School Students in Northern Ethiopia. Health Educ Res Dev. 2013;3(3).

23. Central Statistical Agency (CSA) and ICF International. Ethiopia demographic and health survey 2011. Addis Ababa: Central Statistical Agency and ICF International; 2012:430

24. Dessie Y, Berhane Y, Worku A. High parental monitoring prevents adolescents from engaging in risky sexual practices in Harar, Ethiopia. Glob Health Action. 2014;7.

25. Negeri EL. Assessment of risky sexual behaviours and risk perception among youths in western Ethiopia: the influences of family and peers: a comparative cross-sectional study. BMC Public Health. 2014;14(301).

26. You S, Furlong MJ, Felix E, Sharkey JD, Tanigawa D, Green JG. Relations among school connectedness, hope, life satisfaction, and bully victimization. Psychol Sch. 2008;45(5):446-60.

27. Girma D, Hailu G, Ayana M, Ketema K. Factors early sexual initiation among governmental preparatory school students, Addis Ababa, Ethiopia. J Community Med Health Educ. 2015;5(1):333.

28. Mazengia F, Worku A. Age at sexual initiation and factors associated with it among youths in north East Ethiopia. Ethiop J Health Ethiopa. 2009;23(2): $154-62$

29. Simons $L G$, Burt $C H$, Peterson FR. The effect of religion on risky sexual behavior among college students. Deviant Behav. 2009;30(5):467-85.

30. Gizaw A, Jara DKK. Risky Sexual Practice and Associated Factors among High School Adolescent in Addis Ababa, Ethiopia. Fam Med Med Sci Res. 2014;3(4).

31. Li S, Huang H, Xu G, Cai Y, Huang F, Ye X. Substance use, risky sexual behaviours, and their associations in a Chinese sample of senior high school students. BMC Public Health. 2013;13(295).
32. Rudatsikira E, Ogwell A, Sa S, Muula AS. Prevalence of sexual intercourse among SchoolGoing adolescents in Coast Province, Kenya. Tanzan Health Res Bull. 2007;9:159-63.

33. Mahapatra B, Saggurti N. Exposure to Pornographic Videos and Its Effect on HIV-Related Sexual Risk Behaviours among Male Migrant Workers in Southern India. PLoS One. 2014;9(11).

34. Carroll JA, Kirkpatrick RL. Impact of social media on adolescent behavioral health. Oakland, CA: California Adolescent Health Collaborative; 2011.
Ready to submit your research? Choose BMC and benefit from:

- fast, convenient online submission

- thorough peer review by experienced researchers in your field

- rapid publication on acceptance

- support for research data, including large and complex data types

- gold Open Access which fosters wider collaboration and increased citations

- maximum visibility for your research: over $100 \mathrm{M}$ website views per year

At BMC, research is always in progress.

Learn more biomedcentral.com/submissions 